\title{
Shear capacity assessment of tuff panels strengthened with FRP diagonal layout
}

\author{
${\text { Giancarlo Marcari }{ }^{* 1} \text {, Daniel .V. Oliveira }}^{2}$, Giovanni Fabbrocino ${ }^{3}$, Paulo .B. Lourenço ${ }^{4}$ \\ (1) ISISE, Department of Civil Engineering, School of Engineering, University of Minho, Campus \\ de Azurem, 4800-058, Guimarães, Portugal, E-mail: marcarigia@civil.uminho.pt \\ (2) ISISE, Department of Civil Engineering, School of Engineering, University of Minho, Campus \\ de Azurem, 4800-058, Guimarães, Portugal, E-mail: danvco@civil.uminho.pt \\ (3) StreGa Laboratory, Department SAVA, School of Engineering, University of Molise, 86039, \\ Termoli, Italy, E-mail: giovanni.fabbrocino@unimol.it \\ (4) ISISE, Department of Civil Engineering, School of Engineering, University of Minho, Campus \\ de Azurem, 4800-058, Guimarães, Portugal, E-mail: pbl@civil.uminho.pt
}

${ }^{*}$ Corresponding author: Giancarlo Marcari, ISISE, Department of Civil Engineering, School of Engineering, University of Minho, Campus de Azurem, 4800-058, Guimarães, Portugal, E-mail: marcarigia@civil.uminho.pt. Tel.: +351-253 517 499; Fax: +351- 253510217

\begin{abstract}
A quantitative analysis of the in-plane shear capacity of tuff masonry panels externally reinforced with FRP diagonal layout has been carried out. The objective is to provide a rational approach to the definition of the contributions from masonry and FRP to the lateral in-plane resistance of strengthened panels. Relevant experimental results of monotonic shearcompression tests are carefully analysed. A truss model approach, combined with a proper masonry strength criterion for masonry is proposed and validated. A comparison between computed and experimental data confirms the validity of the procedure in view of practical applications and code recommendations.
\end{abstract}

Keywords: A. Polymer-matrix composites; A. Debonding; C. Analytical modelling; B. Strength; Tuff masonry. 


\section{Introduction}

In the past two decades, the use of externally bonded fibre reinforced polymer (FRP) composites has steadily increased as an efficient technique for structural retrofitting and seismic strengthening of masonry components. Considerable research has been directed to the study of the global response of brick or concrete block masonry strengthened with FRP [1], but tuff masonry panels strengthened with composite materials have not been the subject of much effort. Tuff stone masonry characterises a large part of historic centres located in moderate to high seismic areas in Europe, and in particular in South-central Italy [2]. In the current context (FRP-tuff masonry), the majority of works investigated the use of innovative structural matrices

[3-4]. Still, few experimental investigations have been carried out on tuff masonry strengthened with externally bonded FRP plies applied with diagonal configurations [5]. As a consequence, there is a lack of standard design specifications for FRP-strengthened masonry walls in the case of diagonal configurations $[1,6]$. Various theoretical models based on truss mechanisms have been proposed in order to compute the contribution of the diagonal FRP reinforcement to shear resistance of panels [7-9]. However, with the exception of Stratford [10], masonry shear strength enhancement due to the truss mechanism has not been taken into consideration, thereby neglecting the crucial aspect related to the synergy between FRP and masonry. In addition, the influence of the bond behaviour of FRP in the overall response of the panels still needs to be properly assessed, along with satisfactory quantitative formulations of the shear contributions from both masonry and FRP reinforcement.

The present paper starts from a review and interpretation of the experimental response of tuff masonry panels strengthened with externally bonded FRP plies with diagonal configuration. To this aim, the experimental results obtained by Marcari et al. [5] have been selected and carefully investigated. The main objectives of the study can be summarised as follows:

- investigating the effects of the local (bond) behaviour of the FRP diagonal reinforcement on the global response of the panels;

- performing a quantitative evaluation of masonry and FRP contribution to the shear capacity of the strengthened panels. 
The results are presented in terms axial strain developed in the FRP strip versus the lateral displacement of the wall, and relevant effects of FRP behaviour both on strength capacity and failure mode of the panels are also discussed. An analytical study on the strength contributions of masonry and FRP is carried out by using a truss model approach, combined with a proper shear strength model for masonry. A final comparison between computed and experimental data allowed to obtain relevant results for practical applications.

\section{Quantitative approaches to FRP-strengthened panels}

The shear strength, $V_{S M}$, of FRP-strengthened masonry panels is usually assumed to be made up of two terms:

$$
\mathrm{V}_{\mathrm{SM}}=\mathrm{V}_{\mathrm{m}}+\mathrm{V}_{\mathrm{frp}}
$$

Here $V_{m}$ is the contribution of unreinforced masonry, and $V_{\text {frp }}$ is the contribution of FRP reinforcement. This approach complies with the principles adopted on reinforced masonry and widely accepted for reinforced concrete. Actually in the present state of practice, the value of $V_{m}$ is computed by neglecting the beneficial influence of the FRP due to compression stress flows in the masonry $[1,6]$. Furthermore, no satisfactory background is available on the influence of the FRP diagonal configurations to shear strength performance of masonry. The analysis that follows exploits the approaches used to compute $V_{m}$ and $V_{\text {frp }}$. Attention is limited to panels strengthened with wet layup-based FRP applied in diagonal configurations.

\subsection{Shear contribution from masonry}

Modern codes for masonry structures retrofitted with FRP materials provide design expressions for $V_{m}$ in the case of grid layouts [1,6]. The CNR-DT200 guidelines [6] adopt for $V_{m}$ the expression given by Eurocode 6 [11]. Instead, the ACl $440.7 R$ code [1] explicitly computes $V_{m}$ as the minimum of the failure loads corresponding to shear-controlled and flexure-controlled failure mechanisms.

It is worth noting that some experimental tests showed that the response of FRP-strengthened panels subjected to shear compression loading may be susceptible to diagonal shear tension failure rather than sliding shear failure [5]. It is also observed that FRP may change the failure mode of the specimens, namely from joint sliding to diagonal shear failure [12]. Recently, 
Tomaževič [13] showed that shear resistance assessment as given by Eurocode 6 [11] may provide misleading results in the case of panels governed by diagonal shear failure.

\subsection{Shear contribution from FRP}

Several research studies have focused on developing analytical equations for the evaluation of FRP contribution to the shear capacity of tuff masonry [14]. Recent years have seen the emergence of strut-and-tie models (or truss models) as a powerful approach for the rational design of FRP-strengthened masonry walls [15]. However, some drawbacks due to the lack of identifiable discrete tension-carrying components in the FRP-strengthened walls showing plastic behaviour are recognised, and a thorough validation against experimental results is still not available.

Based on results of a series of tests on masonry panels strengthened with inclined FRP system strip systems, Zhao [9] and Zhao [16] modelled the action of the FRP based on a truss approach. Basically, in the models proposed the shear contribution of the reinforcement was computed from the FRP strip placed along the diagonal in tension, neglecting the contribution of the FRP in compression.

In the work by Prota [7], the predicted $V_{\text {frp }}$ of diagonal reinforcement was computed as the horizontal component of the maximum transferable force $\left(F_{\text {frp }}\right)$ along the tension plies as follows:

$$
V_{\text {frp }}=F_{\text {frp }} \cdot \cos \theta=\epsilon_{\text {fd }} \cdot E_{\text {frp }} \cdot A_{\text {frp }} \cdot \cos \theta
$$

where $A_{\text {frp }}$ is the cross-sectional area of the FRP tension ply, $E_{\text {frp }}$ is the Young's modulus of FRP, $\varepsilon_{\mathrm{fd}}$ is the effective debonding strain of FRP, $\theta$ is the angle of the FRP and the horizontal direction. Alcaino [17] computed $V_{\text {frp }}$ in the case of panels retrofitted with diagonal CFRP strips as:

$$
\mathrm{V}_{\mathrm{frp}}=\alpha \cdot \mathrm{T}_{\mathrm{frp}} \cdot \cos \theta
$$

where $T_{\text {frp }}$ is the maximum tensile force transferrable through the FRP which was determined based on data obtained from shear bond tests, and $\alpha$ is an efficiency factor equal to 1 .

Stratford [10] proposed a truss model to compute the shear load carried by the FRP and the additional vertical compression for concrete and clay masonry walls strengthened with GFRP biaxial strips. In this case, the GFRP was applied on one side and anchored at the edges of the 
specimens. The study is the only one that explicitly accounts for the masonry shear strength enhancement $\left(V_{m}^{\prime}\right)$. It is observed that current available standards and guidelines $[1,6]$ do not provide design expressions for $V_{\text {frp }}$ in the case of diagonal reinforcement.

\section{Experimental background and data}

In this section the experimental campaign carried out by some of the authors since 2007 is briefly reviewed. Further information about the test setup and instrumentation, masonry and FRP materials properties, as well as a discussion of the overall behaviour of the panels, has been presented in [5].

The test program included four as-built panels and seven strengthened panels. The nominal dimensions of each specimen were $1570 \mathrm{~mm}$ high, $1480 \mathrm{~mm}$ wide, $530 \mathrm{~mm}$ thick. All walls were characterised by partial connection between the external leaves. Shear loading was applied monotonically under displacement control once the axial load $\left(\mathrm{N}_{0}\right)$ was imposed.

The strengthening consisted of diagonal $200 \mathrm{~mm}$ wide FRP plies bonded on the two sides of the panel (Figure 1a). The parameters investigated were the type (carbon and glass sheet) and amount of FRP reinforcement (one layer and two layers for each diagonal ply). Each test on strengthened panels is defined by a three-letter code, $(C)$ for carbon or $(G)$ for glass strips, followed by the number of FRP layers used - (LD) for one layer, (HD) for two layers - followed by (a) or (b) to distinguish the replicate of the two specimens identically strengthened (i.e., two equal specimens were tested for each diagonal layout, with the exception of LD GFRP).

The nominal tensile strength of CFRP and GRP was $3450 \mathrm{MPa}$ and $1320 \mathrm{MPa}$, respectively. The values of axial stiffness $\left(E_{\text {frp }} \times t_{f}\right)$ of the diagonal reinforcement are reported in Table 1, where $E_{\text {trp }}$ is the Young's modulus of the FRP and $t_{f}$ is the ply thickness. The diagonal plies were anchored at the edges thorough horizontal FRP plies either fully wrapped around the panel section, or partially-wrapped (called herewith U-wrap). In the latter system, the horizontal plies were terminated at the middle of the lateral side of the panels as schematically illustrated in Figure 1b. The fully wrapped system was used for specimens C2a and G2a. In all tests, the panel surfaces were pre-treated by a coating primer in order to improve the adhesion of the FRP plies to masonry substrate.

The FRP reinforcement strains were measured using $5 \mathrm{~mm}$ gauge-length strain gauges (SGs), 
placed along the centreline as shown in Figure 1a. The measurement range of the SGs was limited to $\pm 5 \times 10^{-3}$. Typically, only side $A$ of the panel was gauged completely, with the exception of panels $\mathrm{C} 2 \mathrm{a}$ and $\mathrm{G} 2 \mathrm{a}$ which were gauged on both sides.

The response of the unstrengthened panels was governed by the formation and development of shear cracks, passing through mortar joints and stones. The strengthened panels exhibited shear behaviour, with diagonally oriented shear cracks, usually accompanied by spalling of the stones along the compressed side of the specimens. Moreover, no crushing of the diagonal compression in the masonry was observed.

The shear force vs. horizontal displacement curves $(\mathrm{V}-\delta)$ of the as-built and strengthened panels are presented in Figure 2. Also, the average V- $\delta$ curve which is representative of the average experimental behaviour of the as-built panels is shown in the same figure.

The average lateral resistance of the as-built panels $\left(\mathrm{V}_{\max }\right)$ approached $132 \mathrm{kN}$, with a standard deviation equal to $34.9 \mathrm{kN}$ and a coefficient of variation $\mathrm{CoV}$ of $26 \%$. It is remarked that the tested specimens have a significant amount of "built-in" variability, as typical of multiple leaf tuff masonry [19]. Despite the limited amount of data a central tendency of the strength values was found. Moreover, from comparison of experimental shear-displacement curves (V- $\delta)$ with the average curve illustrated in Figure 2, it can be observed that the average peak load $\left(\mathrm{V}_{\max }\right)$ is close to that of panels $\mathrm{P \# 2}$ and $\mathrm{P \# 3}$. $\mathrm{V}_{\max }$ is also consistent with lateral strength values found in [18] for the type of masonry considered. These results suggest that $V_{\max }$ can be reasonably assumed as a basis for strength comparisons.

The shear strength increase due to the diagonal reinforcement is estimated as $\Delta \mathrm{V} / \mathrm{V}_{\max }$, where $\Delta \mathrm{V}=\mathrm{V}_{\max , \text { str. }}-\mathrm{V}_{\max }$ and $\mathrm{V}_{\max , \text { str. }}$ is the shear resistance of the strengthened panels. The values are reported in Table 1. It can be observed that C2 panels show the highest increase equal to $54 \%$, whereas G1a show the lowest increase of about $20 \%$. The strength increase of panels $\mathrm{C} 2$ is almost twice that of panels $\mathrm{C} 1$, whereas panels $\mathrm{G} 2$ provide a small strength increase when compared to $\mathrm{G} 1$ ( $24 \%$ instead of $18 \%)$.

\section{Experimental response of FRP strengthened tuff panels}

The strain profiles of the FRP reinforcement are discussed with respect to the global V- $\delta$ response of the panels. The strain profile is a plot of an experimental strain measure against the 
lateral displacement of the specimen. It is noted that the strain profiles are shown for the plies applied on one panel side. Results from FRP strain measures were also combined with the information gathered from visual inspection of the FRP debonding during the tests. In the following, debonding of FRP from the masonry is meant as shear delamination failure.

\subsection{Panel C1a}

The strain profiles on side A are shown in Figure 3. One of the characteristics of the observed behaviour was a partial detachment of the U-wrap ply edge that occurred at the upper lateral side of the specimen, at a displacement $\delta$ of only $2.5 \mathrm{~mm}(\mathrm{drift}=0.14 \%)$ and load $\mathrm{V}=30 \% \mathrm{~V}_{\max , \text { str. }}$. This failure caused a jump in the strain profiles as shown in Figure 3a and Figure 3b. However, the tension ply was still able to carry load. The debonding of the compressed ply started at about $\delta=8.0 \mathrm{~mm}(0.50 \%)$ and $\mathrm{V}=75 \% \mathrm{~V}_{\text {max,str. }}$ (Figure $\left.3 \mathrm{a}\right)$. The average debonding strain for the ply in compression was in the range $(-0.78 ;-0.95) \times 10^{-3}$. The tensile strain attained the peak value $+3.02 \times 10^{-3}$ when $V$ reduced $15 \%$ with a $\delta=22 \mathrm{~mm}(1.40 \%)$, see Figure $3 \mathrm{~b}$ and Figure $3 \mathrm{c}$.

\subsection{Panel C1b}

The strain profiles on side A are shown in Figure 4. The plies became significantly active at around a $\delta=10 \mathrm{~mm}$ (drift=0.60\%). The debonding of the compressed ply was first detected by SG\#3 and SG\#6 at a $\delta=13 \mathrm{~mm}(0.80 \%)$ and $V$ approached $90 \% \mathrm{~V}_{\text {max,str. }}$ (Figure $\left.4 \mathrm{a}\right)$. The average debonding strain of the compressed ply was in the range $(-1.08 ;-1.21) \times 10^{-3}$.

The maximum tensile strain averaged $+3.06 \times 10^{-3}$ (Figure $4 \mathrm{~b}$ ) when $\mathrm{V}$ reduced $10 \%$ at $\delta=19 \mathrm{~mm}$ (1.30\%). Then, the panel showed a rapid loss in strength (Figure 4c). However, the tensile plies were able to carry loading up to a $\delta=22 \mathrm{~mm}(1.40 \%)$, when one edge of the U-Wrap ply detached from the lateral side of the specimen. The damage at $1.40 \%$ drift is presented in Figure 10a.

\subsection{Panel C2a}

The strain profiles from side A are illustrated in Figure 5. The onset of debonding of the compressed ply initiated at a $\delta=5.0 \mathrm{~mm}$ (drift=0.35\%), as detected by SG\#1 and SG\#3 (Figure $5 a)$. The average debonding strain was in the range $(-0.70 ;-1.10) \times 10^{-3}$ and occurred at 
displacements between $5 \mathrm{~mm}(0.35 \%)$ and $9.4 \mathrm{~mm}(0.6 \%)$. The compressed ply started to buckle locally at a $\delta=9.5 \mathrm{~mm}$.

As for the tensile ply, the drop of strain seen in Figure $5 \mathrm{~b}$ was due to a sudden debonding that occurred at $\delta=15 \mathrm{~cm}$ (drift=1.0\%), with a strength decay of about $8 \%$ (Figure $5 \mathrm{c}$ ). The maximum tensile strains occurred at $\delta=21.1 \mathrm{~mm}(1.3 \%)$, with a load decay of $18 \%$. The peak tensile strain along the two panel sides averaged $+2.81 \times 10^{-3}$.

\subsection{Panel $\mathrm{C} 2 \mathrm{~b}$}

The strain profiles of the diagonal plies from side A are shown in Figure 6. The compressed ply started debonding at a $\delta=13.0 \mathrm{~mm}$ (drift=0.80\%) and $\mathrm{V}=70 \% \mathrm{~V}_{\max , \text { str. }}$ (see SGs \#1 and \#3 in Figure 6a). The average debonding strain was in the range $(-0.71 ;-1.10) \times 10^{-3}$.

The maximum tensile strains attained $+2.10 \times 10^{-3}$ at a $\delta=30.0 \mathrm{~mm}(1.90 \%)$ when $\vee$ dropped $8 \%$ (Figure 6b). Drops in both strains profiles and V- $\delta$ curve were seen at $\delta=33 \mathrm{~mm}(2.1 \%)$ and $\mathrm{V}=15 \% \mathrm{~V}_{\mathrm{max}, \text { str. }}$ (Figure $6 \mathrm{c}$ ), due to a large crack developed along the compressed side of the panel. Under increasing lateral drift, the U-wrap ply edge detached from the top lateral side of the panel and a major vertical crack developed in the pier, as illustrated in Figure 10b.

\subsection{Panel G1a}

The strain profiles on side A are shown in Figure 7. The debonding of the compressed plies was detected first by SGs\#6 and \#3 in Figure $7 \mathrm{a}$, at a $\delta=7.5 \mathrm{~mm}$ (drift=0.47\%) and $\mathrm{V}=80 \% \mathrm{~V}_{\max , \mathrm{str}}$. The average debonding strain of the compressed ply was in the range $(-1.25 ;-1.31) \times 10^{-3}$. The tensile strains approached their peak when the drop in strength on the V- $\delta$ softening branch was in the range $20 \%-25 \%$ and the lateral drift between $1.00 \%$ and $1.15 \%$ (Figure $7 \mathrm{~b}$ and Figure 7c). After that, the tensile ply suffered rupture near the location of SG\#7 (Figure 10c). As a consequence a sudden drop in strength was observed in the V- $\delta$ curve (Figure 7c).

\subsection{Panel G2a}

The strain profiles on side B are illustrated in Figure 8. The onset of debonding of compressed

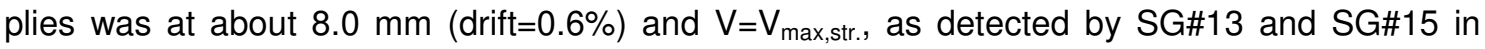
Figure $8 \mathrm{a})$. The compressed plies fully debonded at around $\delta=13 \mathrm{~mm}(0.86 \%)$. The debonding strains values ranged between $-0.81 \times 10^{-3}$ and $-0.95 \times 10^{-3}$. 
At the peak load, readings of SG\#16 on the tensile ply exceeded $+5.0 \times 10^{-3}$ (Figure $8 b$ ). However, no FRP rupture occurred. From analysis of tensile strain profiles on the two panel sides it was observed that the peak strains were attained at a $\delta=20-25 \mathrm{~mm}(1.3 \%-1.6 \%)$ and $\mathrm{V}=(25 \%-30 \%) \mathrm{V}_{\text {max,str. }}$ (Figure 8c).

\subsection{Panel G2b}

The strain profiles of the diagonal plies from side A are shown in Figure 9. No strains were recorded for SG\#6 and are hence not shown. The compressed ply started to debond when V approached $75 \%$ of $V_{\max , \text { str. }}$ as shown by the strain of SG\#8 in Figure 9a. The average debonding strain can be assumed equal to $-0.98 \times 10^{-3}$.

The horizontal ply edge detached on the top lateral side of the specimen at a $\delta=15 \mathrm{~mm}$ (drift $=0.95 \%$ ) and a lateral strength reduced of $20 \%$ (Figure 9c). A subsequent drop in the V- $\delta$ occurred at $\delta=16.8 \mathrm{~mm}(1.0 \%)$ due to the rupture of the tensile ply on side $\mathrm{B}$. The maximum tensile strains measured on side $A$ averaged $+4.09 \times 10^{-3}$ (Figure 9b).

\section{Discussion of the test results}

The experimental observation showed that the FRP reinforcement did not seem to have any significant impact on the initial lateral stiffness of the panels (see Figure 2). Upon increasing lateral displacement, local FRP debonding occurred which typically started propagating from the centre of the panels.

Let $\xi_{\mathrm{deb}}=\mathrm{V}_{\mathrm{deb}} / \mathrm{V}_{\mathrm{max} \text {,str. }}$, be the ratio between the lateral force at the debonding of the compressed plies $\left(\mathrm{V}_{\mathrm{deb}}\right)$, and the peak load $\left(\mathrm{V}_{\mathrm{max}, \mathrm{str} .}\right)$. The wall lateral drifts and the $\xi_{\text {deb }}$ ratios exhibited at debonding of the compressed plies are summarised in Table 1. Debonding of the compressed plies of CFRP- and GFRP-strengthened panels occurred on the ascending branch of the V- $\delta$ diagram for $\xi_{\mathrm{deb}}=73 \%-87 \%$ and $\xi_{\mathrm{deb}}=83 \%-100 \%$, respectively. The strengthened panels showed also similar debonding strain values. In fact, the strains were from $-0.70 \times 10^{-3}$ and $-1.21 \times 10^{-3}$ in CFRP, and from $-0.81 \times 10^{-3}$ and $-1.31 \times 10^{-3}$ in GFRP. Moreover, the lateral drift at which debonding of compressed plies occurred ranged between $0.25 \%$ and $0.90 \%$ and seems not to be correlated with the FRP type or FRP density.

As for the tensile plies, the strains in the FRP showed a non linear behaviour characterised by an irregular path around the peak lateral force (Figure 5b, Figure 9b). The lateral drifts 
developed at the peak tensile FRP strains $\left(\varepsilon_{\max }\right)$ have been summarised in Table 1 . This lateral drift does not vary much with the CFRP density with an average of $1.5 \%$, while it varies from $0.90 \%$ to $1.60 \%$ in GFRP-strengthened panels.

The last column of Table 1 gives the reduction of lateral strength in correspondence of $\varepsilon_{\max }$ calculated as $\mathrm{S}_{\mathrm{r}}=\mathrm{V}_{\varepsilon, \max } / \mathrm{V}_{\max , \text { str. }}$, where $\mathrm{V}_{\varepsilon, \max }$ is the lateral force that corresponds to $\varepsilon_{\max }$. The experimental results indicate that the peak tensile strains occurred when the $V-\delta$ curves displayed the post-peak behaviour (Figure $5 b$, Figure $8 b$ ). The strength reduction was $15 \%$ for CFRP and ranged from $11 \%$ to $30 \%$ for GFRP. At that stage, the masonry resulted severely damaged and the diagonal tensile plies debonded from the substrate.

While not shown, an important phenomenon that has been found in the behaviour of panels gauged on both sides ( $\mathrm{C} 2 \mathrm{a}$ and $\mathrm{G} 2 \mathrm{a}$ ) is that the strains measured at the same location on the opposite side of the walls followed a similar pattern. As a consequence, the results in terms of FRP debonding and peak strains on both sides of the panel were remarkably similar.

The lateral displacement of the panel caused direction changes in the diagonal tensile plies as can be seen from Figure 10a and Figure 8. As a consequence, the diagonal plies in tension were subjected to axial force and bending moment which led, in the case of G1a and G2b panels, to the rupture of the strengthening. It was found that the FRP usually failed below the middle part of the panel, between the gauge points \#5 and \#7 (Figure 10c). Moreover, the FRP rupture occurred when the lateral load reduced of $20 \%-25 \%$ on the softening branch of the loaddisplacement curve.

Finally, it is remarked that the anchorage systems resulted effective in preventing edge debonding of the diagonal plies. As a result, the full shear capacity of the strengthened panels was mobilised.

\section{$6 \quad$ Analytical investigation}

\subsection{Shear strength provided by FRP}

The simple truss based model in Figure 11 is adopted to provide an estimation of the shear contribution due to $\operatorname{FRP}\left(\mathrm{V}_{\text {frp }}\right)$, and the related additional vertical load in the masonry panel due to FRP reinforcement $\left(\mathrm{N}_{\mathrm{m}, \mathrm{fr}}\right)$, on the analogy with Stratford's approach [10]. Basically, the model assumes that the shear carrying mechanism associated with the FRP is characterised by a 
vertical masonry compression strut and a diagonal FRP tension tie. Moreover, the contribution of the diagonal compressed plies is assumed to be negligible. The tension force that develops in the FRP diagonal tie $\left(F_{\text {frr }}\right)$, expressed as a function of the lateral displacement $(\delta)$, is computed as follows:

$$
\mathrm{F}_{\text {frp }}(\delta)=\mathrm{n} \cdot\left(\mathrm{E}_{\mathrm{frp}} \cdot \mathrm{w}_{\mathrm{frp}} \cdot \mathrm{t}_{\mathrm{frp}}\right) \cdot \epsilon_{\mathrm{frp}}(\delta)
$$

where $n$ is the number of tensile plies, $E_{\text {frr }}$ the elastic modulus of the $F R P, w_{\text {frp }}$ and $t_{\text {frp }}$ respectively the width and the thickness of each single FRP tensile ply, and $\varepsilon_{\text {frp }}(\delta)$ is the axial strain of the FRP in tension that has been computed from the experimental strain measures.

It was observed that experimental axial strain $\left(\varepsilon_{\text {frp }}\right)$ - displacement $(\delta)$ curves varied along the entire FRP ply. However, these curves showed a similar trend and did not differ much among them, as it can be seen in Figure 3 to Figure 9. Moreover, the experimental strains were symmetrical for the side A and side B of both specimens C2a and G2a. Therefore, $\varepsilon_{\text {frp }}(\delta)$ in Eq. (4) computed as the average of the experimental strains measured over the entire ply in tension appears to be acceptable. More specifically, when strain measures were available from only side A of the panel, $\varepsilon_{\text {frp }}(\delta)$ in Eq. (4) has been computed as the average of the experimental strains of SGs \#2, \#4, \#5 and \#7, see Figure 1a. In the case of FRP strains available from the two sides of the specimen, $\varepsilon_{\text {frp }}(\delta)$ has been computed as the average of the strains on side $A$ (SGs \#2, \#4, \#5, \#7) and side B (SGs \#9, \#11, \#14, \#16).

The FRP strength contribution $\left(\mathrm{V}_{\mathrm{frr}}\right)$ and the force in the vertical strut of this idealized truss are defined by the conditions of static equilibrium. From the horizontal equilibrium of the node point $\mathrm{P}$ in Figure 11, the shear strength due to FRP is:

$$
V_{\text {frp }}(\delta)=F_{f r p}(\delta) \cdot \cos \theta
$$

where $\theta=46.69^{\circ}$ is the angle between the ply and the horizontal direction. From the vertical equilibrium, the force in the masonry strut is:

$$
N_{\text {frp }}(\delta)=F_{\text {frp }}(\delta) \cdot \sin \theta
$$

The masonry shear strength depends upon the vertical load $N_{o}+N_{m \text {,frp }}$ that can be evaluated by using masonry strength domains as shown in section 6.2. In Figure 12, the FRP shear contribution $V_{\text {frp }}$ is plotted against the lateral displacement $\delta$ and compared with the 
experimental $V-\delta$ curves. The figure shows that $V_{\text {frp }}(\delta)$ is characterised by an approximately linear behaviour, followed by a nonlinear path as the V- $\delta$ diagram of the strengthened panels approach the peak load. Comparing the curves plotted in Figure $12 \mathrm{a}$ or Figure $12 \mathrm{~b}$, it is interesting to note that the peak of $V_{\text {frp }}$ and the peak of the $(\mathrm{V}-\delta)$ curves of as-built and strengthened panels occurred for different lateral displacement. Moreover, when fully wrapping anchorage was used (panels C2a and G2a) the post-peak of the $V_{\text {frp }}-\delta$ diagrams exhibited softening behaviour (Figure 12b, Figure 12d).

\subsection{Shear strength provided by masonry}

Test results are used to compare shear strength equations proposed in literature, respectively associated to diagonal tension shear failure and flexural failure mechanism. Since no sliding failure was detected, the shear strength associated to sliding mechanism is not taken into consideration. The equation proposed by the Italian seismic code NTC (2008) [20] has been used to compute the shear resistance of the panel corresponding to the diagonal tension failure:

$$
\mathrm{V}_{\mathrm{m} \text {,diag.shear }}=\mathrm{A}_{\mathrm{w}} \cdot \frac{1.5 \mathrm{Tod}}{\mathrm{b}} \cdot \sqrt{1+\frac{\sigma_{\mathrm{o}}}{1.5 \mathrm{~T}_{\mathrm{od}}}} \quad \mathrm{b}=\frac{\mathrm{H}}{\mathrm{B}} \quad 1 \leq \mathrm{b} \leq 1.5
$$

in which $B$ is the base, $H$ the height of the panel; $A_{w}$ the area of the horizontal cross-section of the panel, $\sigma_{0}$ is the average compression stress in the horizontal cross-section of the panel, $T_{o d}$ is the masonry shear strength which is related to a conventional tensile strength of masonry to be determined by shear tests on walls piers ([20]).

The lateral strength corresponding to flexural failure (i.e., overturning of the wall and simultaneous crushing of the compressed toe of the wall), is calculated from equilibrium conditions of the panel and assuming an equivalent rectangular stress block for the masonry [21]:

$$
\mathrm{V}_{\mathrm{m}, \mathrm{flexural}}=\Psi \cdot \frac{\mathrm{B}^{2} \cdot \mathrm{t}}{\mathrm{H}} \cdot \frac{\sigma_{\mathrm{o}}}{2} \cdot\left(1-\frac{\sigma_{0}}{0.85 \mathrm{f}_{\mathrm{m}}}\right)
$$

where $\mathrm{H}$ is the wall height, $\mathrm{f}_{\mathrm{m}}=1.10 \mathrm{MPa}$ is the compressive strength of masonry, $\sigma_{0}$ is the average compression stress and $\psi$ is a parameter which describes the boundary conditions, taking a value of 2 for fixed-ended walls.

No experimental tests were carried out in order to evaluate $\mathrm{T}_{\mathrm{od}}$. Therefore, the value $\mathrm{T}_{\mathrm{od}}=0.038$ MPa has been selected from literature works (Db Murature Unina-DIST [22]). The choice to use 
that value of $T_{\text {od }}$ results in good agreement with the values recommended by the NTC (2008) [20]. By assuming for the vertical load the value $\mathrm{N}=\mathrm{N}_{0}$, the calculated shear resistance associated to diagonal tension shear failure [Eq. (7)] is of $130 \mathrm{kN}$, and in the case of flexural failure [Eq. (8)] it is equal to $172 \mathrm{kN}$. Therefore, good agreement between the result of Eq. (7) and the average experimental strength of the as-built panels $\left(\mathrm{V}_{\max }=132 \mathrm{kN}\right)$ is found. Based on this result, and considering that the strengthened masonry walls failed typically in diagonal shear, Eq. (7) is selected to predict the masonry contribution to shear resistance of the strengthened panels. The validity of this assumption is examined in subsequent section.

\subsection{Validation of the theoretical model}

The experimental shear strength of the strengthened panels is given as:

$$
\mathrm{V}_{\mathrm{SM}}=\mathrm{V}_{\mathrm{m}}{ }_{\mathrm{m}}+\mathrm{V}_{\mathrm{frp}}
$$

where $V_{m}^{\prime}$ is the masonry shear strength under the increased vertical load $N_{o}+N_{m, \text { frp }}$ due to truss mechanism. In the following analysis the maximum values of the functions $F_{\text {frp }}(\delta), V_{\text {frp }}(\delta)$ and $\mathrm{N}_{\mathrm{m}, \mathrm{frp}}(\delta)$ have been considered. It is worth noting that these maxima correspond to the attainment of the maximum tensile force $F_{\text {frp }}$ of Eq. (4). Accordingly, the shear strength $V_{m}^{\prime}$ in Eq. (9) has been estimated with Eq. (7), assuming $N=\max \left(N_{0}+N_{m, \text { frp }}\right)$.

The computed strength values $F_{\text {frp }}, V_{\text {frp }}$ and $V_{m}^{\prime}$, the sum $V_{S M}$, and the ratio $V_{S M} / V_{\text {max,str. are given }}$ in Table 2. A reasonable correlation between the computed values of $V_{S M}$ and the experimental results $\left(\mathrm{V}_{\mathrm{max}, \text { str. }}\right)$ is found. Therefore, the analytical model described above, together with Eq. (7) for estimating the masonry shear strength appears satisfactory. It should be noted that the analytical model rests on the extreme idealization of the interaction behaviour of the FRPmasonry system, as the effect of the eccentricity of the axial force $N_{\text {frp }}$ has not been considered in the model. However, the approximation made led to results on the conservative side (see Table 2).

\section{Results and discussion}

\subsection{Comparative analysis}

The calculated values of $N_{m \text {,frp }}$ are given in Table 2, where the experimental vertical loads $N_{0}$ imposed at the top of the panels are also reported. The results show that the increment of the 
vertical load due to FRP truss mechanism was of about $8.5 \%$ and $14.0 \%$ for $\mathrm{C} 1$ and $\mathrm{C} 2$ panels, respectively. As for GFRP, the increment averaged $2.5 \%$ and $4.5 \%$ for $\mathrm{G} 1$ and $\mathrm{G} 2$, respectively. By comparison between $V_{m}^{\prime}$ of the strengthened panels and $V_{\max }=132 \mathrm{kN}$ of the as-built panels, the shear strength enhancement of masonry $\left(\mathrm{V}_{\mathrm{m}}^{\prime}-\mathrm{V}_{\max }\right) / \mathrm{V}_{\max }$ due to the increased vertical load $\mathrm{N}_{0}+\mathrm{N}_{\text {frp }}$ has been evaluated. Results are reported in Table 2. The masonry strength enhanced about $2.5 \%$ and $4.5 \%$ in the case of panels $\mathrm{C} 1$ and $\mathrm{C} 2$ respectively, and about $0.50 \%$ in the case of panels $\mathrm{G} 1$ and $\mathrm{G} 2$.

The importance of the contributions of masonry and FRP to lateral resistance of the strengthened panels has been detailed in Table 2 by calculating the ratios $V_{m}^{\prime} / V_{\text {max,str. }}$ and $\mathrm{V}_{\mathrm{trp}} / \mathrm{V}_{\text {max,str. }}$. It can be seen that the FRP contribution was greater for CFRP-strengthened panels (25\% for panels C2) than GFRP-strengthened panels (6\% for panel G1a). In detail, the contribution of FRP increased about $50 \%$ from panels $\mathrm{C} 1$ to panels $\mathrm{C} 2$, and about $65 \%$ from $\mathrm{G} 1$ to G2. Moreover, the contribution of the reinforcement for $\mathrm{C} 1$ panels is about $180 \%$ greater than that of $\mathrm{G} 1$, while the contribution for $\mathrm{C} 2$ panels was about $160 \%$ greater than that of $\mathrm{G} 2$ panels. Figure 13a shows a plot of $V_{m}^{\prime} / V_{m a x, s t r .}$ versus $V_{\text {frp }} / V_{m a x, \text { str. }}$ It can be observed that, upon increasing the FRP axial stiffness, the shear strength contribution $\mathrm{V}_{\mathrm{m}}$, due to masonry tends to reduce (in percentage), resulting in an increase of $\mathrm{V}_{\mathrm{frp}}$.

Comparisons of results have been also performed using the axial force-shear force (N-V) interaction diagram of the masonry panel. Equation (7) and Equation (8) were used respectively to plot shear and flexural strength domains in Figure 13b. In this figure the point representing the average experimental behaviour of the unstrengthened panels $(\mathrm{N}=385 \mathrm{kN}$ and $\mathrm{V}=132 \mathrm{kN})$ lies on the diagonal shear failure limit. Figure $13 \mathrm{~b}$ shows also the $\mathrm{N}-\mathrm{V}$ pairs of the strengthened panels, with $\mathrm{N}=\mathrm{N}_{0}+\mathrm{N}_{\text {frp }}$ and $\mathrm{V}=\mathrm{V}_{\text {max,str. }}$. It can be observed that the points representing panels strengthened with high FRP axial stiffness $\mathrm{E}_{\mathrm{frp}} \times \mathrm{t}_{\mathrm{f}}$ (i.e., $\mathrm{C} 1$ and $\mathrm{C} 2$ ) were likely to lie beyond the flexural strength limit of the unstrengthened panel.

Although the limited sample size, a simple regression analysis is carried out to investigate a possible relation between $\mathrm{N}$ and $\mathrm{V}$ of the strengthened panels. The regression line is plotted in Figure $13 \mathrm{~b}$. The coefficient of determination $R^{2}$ is found to be lower than 0.5 , therefore the analysis seems to suggest a weak correlation between $\mathrm{N}$ and $\mathrm{V}$. However, from Figure $13 \mathrm{~b}$ it is 
possible to note that for all types of tested FRP reinforcement, the level of vertical compression in the masonry increases with the FRP axial stiffness. This result appears interesting since it suggests a limit to the maximum amount (FRP axial stiffness) of diagonal reinforcement that can be applied to the wall. In particular, the FRP should be designed in order that the increased compressive load in the masonry due to the activation of the FRP confinement should not exceed that of the node point $A$ in Figure 13b. For the tested panels the point $A$ is characterised by $\mathrm{N}=507 \mathrm{kN}$, i.e., $1.30 \mathrm{~N}_{0}$. Beyond this limit, any additional FRP amount would be non efficient. The FRP strength contribution $\mathrm{V}_{\mathrm{frp}}$ computed with the truss model [Eq. (5)] has been compared with the FRP strength computed as difference $\Delta \mathrm{V}^{\prime}=\mathrm{V}_{\text {max,str. }}-\mathrm{V}_{\mathrm{m}}$, see also Figure $13 \mathrm{~b}$. Table 2 shows the values of $\Delta \mathrm{V}^{\prime}$ and the ratio $\mathrm{V}_{\text {frp }} / \Delta \mathrm{V}^{\prime}$. The correlations show that the gain in strength $\Delta \mathrm{V}$ ' achieved by panels $\mathrm{C} 1 \mathrm{a}, \mathrm{C} 2 \mathrm{a}$ and $\mathrm{G} 2 \mathrm{~b}$ was represented by the FRP contribution. For panels $\mathrm{C} 1 \mathrm{~b}, \mathrm{C} 2 \mathrm{~b}, \mathrm{G} 1 \mathrm{a}$ and $\mathrm{G} 2 \mathrm{a}$, the FRP contribution to the shear strength was lower, on average equal to about $45 \%$ of $\Delta \mathrm{V}^{\prime}$. The remaining part $55 \%$ of $\Delta \mathrm{V}^{\prime}$ represents the shear strength enhancement of masonry but, according to the analytical analysis, such enhancement was found negligible (i.e., $V_{m}$ close to $V_{\max }$ ). The discrepancy is probably due to the fact that the analytical prediction may tend to underestimate the shear strength enhancement of masonry. Further research is needed to confirm these observations.

The obtained data allow $V_{\text {frp }}$ to be estimated from the lateral resistance of as-built specimens. To this end, the ratio $V_{\text {frp }} / V_{\max }$ has been calculated, with $V_{\max }=132 \mathrm{kN}$. Results are shown in Table 2. It can be observed that $\mathrm{V}_{\text {frp }}$ resulted equal to $22 \%$ and $38 \%$ of $\mathrm{V}_{\max }$ for $\mathrm{C} 1$ and $\mathrm{C} 2$ panels, and about $7 \%$ and $12 \%$ for G1 and G2 panels, respectively.

\subsection{Tensile force in the FRP}

The experimental maximum tensile force $F_{\text {frp }}$ developed by the diagonal plies (Table 2) has been compared with the value computed as $A_{\text {frp }} \times f_{f f d}$, where $A_{\text {frp }}$ is the FRP area, and $f_{f f d}$ is the design bond strength of masonry elements strengthened by FRP material computed according to CNR-DT200 [6] and given as:

$$
f_{f f d}=A_{w} \cdot \frac{0.17}{Y_{f, d} \cdot \sqrt{Y_{m}}} \cdot \sqrt{\frac{E_{f} \cdot \sqrt{f_{m k} \cdot f_{m t m}}}{t_{f}}}
$$


where $f_{m k}$ and $f_{m t m}$ are the characteristic compressive strength and the average tensile strength of masonry, respectively, and $\gamma_{\mathrm{t}, \mathrm{d}}$ the partial safety factors for debonding and $\gamma_{\mathrm{m}}$ the masonry partial factor $\left(\gamma_{t, d}\right.$ and $\gamma_{m}$ are taken as unity). The strength $f_{m k}$ has been computed according to the equation proposed in [23] for multiple leaf tuff panels, resulting equal to $0.95 \mathrm{MPa}$. In absence of direct tensile tests, $\mathrm{f}_{\mathrm{mtm}}$ has been assumed as the tensile strength of the stones $\left(\mathrm{f}_{\mathrm{t}, \mathrm{tuff}}\right)$, in accordance with CNR-DT200 recommendations. No data on $\mathrm{f}_{\mathrm{t}, \mathrm{tuff}}$ were available. An empirical formula which is commonly used to evaluate the tuff stone tensile strength $f_{t, t u f f}$ from the tuff stone compressive strength $f_{c, \text { tuff }}$ (i.e., $f_{t, \text { tuff }}=0.1 f_{c, \text { tuff }}$ ), with $f_{c \text {,tuff }}=3.71 \mathrm{MPa}$ obtained experimentally, has been used. The results showed that the experimental $F_{\text {frp }}$ was about 4 and 5 times greater than in CNR-DT for panels $\mathrm{C} 1$ and C2, respectively; 2.8 times and 3.7 times greater than in CNR-DT for panels $\mathrm{G} 1$ and $\mathrm{G} 2$, respectively. Comparing now the $F_{\text {frp }}$ with the ultimate tensile strength $\left(F_{\text {ult }}\right)$ of the reinforcement, it can be shown that $F_{\text {frp }}$ is equal to $17 \%$ of $\mathrm{F}_{\text {ult,CFRP }}$ in $\mathrm{C} 1$ and $\mathrm{C} 2$ panels, and $21 \%$ of $\mathrm{F}_{\text {ult,GFRP }}$ in $\mathrm{G} 1$ and $\mathrm{G} 2$ panels.

\section{Conclusions}

The present paper reports a contribution to the development of reliable quantitative models for design of FRP diagonal layouts for shear strengthening of masonry walls. Attention has been focused on multiple-leaf tuff masonry panels. Analysis of the local (strain) behaviour of the FRP reinforcement represents the key aspect of the paper. The experimental data have been used to propose an analytical approach based on a simple truss model, improved with a well established masonry shear strength model [20], in order to estimate the shear resistance contribution of masonry $\left(\mathrm{V}_{\mathrm{m}}^{\prime}\right)$ and FRP $\left(\mathrm{V}_{\mathrm{fr}}\right)$. A number of simplifying assumptions have been adopted. However, the improved model provided good and conservative results compared with experimental outcomes. In view of practical applications and extensive theoretical and experimental refinements, the following conclusions can be made:

- The FRP tensile force $F_{\text {frp }}$ resulted about $20 \%$ of the ultimate tension force of both CFRP and GFRP strengthened panels. $F_{\text {frp }}$ was approximately 4.5 and 3 times greater than that computed according to available relevant design guidelines, respectively for CFRP and GFRP. 
- The FRP shear strength contribution $\left(V_{\text {frp }}\right)$ versus the lateral displacement $(\delta)$ of the panels showed a nonlinear behaviour. Moreover the peak values of the shear strength contributions of masonry and FRP occurred for different lateral displacements.

- The shear resistance of the panels was greatly enhanced by the FRP diagonal reinforcement.

- The largest contribution to the lateral resistance of the strengthened panels is represented by the masonry shear strength. $\mathrm{V}_{\mathrm{m}}$ r resulted no less than $70 \%$ of $\mathrm{V}_{\mathrm{max}, \text { str. }}$.

- The vertical compression in the walls increases with the FRP axial stiffness.

- The masonry strength enhancement was found to be about $2.5 \%-4.5 \%$ for panels $\mathrm{C} 1$ and $\mathrm{C} 2$ and $0.50 \%$ for panels $\mathrm{G} 1$ and $\mathrm{G} 2$.

- $V_{\text {frp }}$ depended on the type and axial stiffness of the reinforcement. The FRP contribution ranged from $26 \%$ of $\mathrm{V}_{\mathrm{max}, \text { str. }}$. (panels $\mathrm{C} 2$ ) to $6 \%$ of $\mathrm{V}_{\mathrm{max}, \text { str. }}$ (panel $\left.\mathrm{G} 1 \mathrm{a}\right)$ ).

- Strengthening with FRP diagonal systems can be achieved only if there is sufficient additional compressive capacity in the masonry to allow for the additional vertical load due to FRP truss mechanism.

Further research is needed to confirm the experimental observations and to validate the proposed model, by analysing different types of masonry typologies. Refined numerical analysis are certainly of paramount relevance in order to provide insight into a) interaction mechanisms between masonry and FRP, b) shear resistance mechanisms mobilised by the masonry when proper anchorage of the FRP strengthening system is ensured.

\section{References}

1. ACl 440.7R-10. Guide for the design and construction of externally bonded FRP systems for strengthening concrete structures. ACl Committee 440, Farmington Hills, Michigan, USA, 2010. 
2. Calderoni A, Cecere G, Cordasco EA, Guerriero L, Lenza P, Manfredi G. Metrological definition and evaluation of some mechanical properties of post-medieval Neapolitan yellow tuff masonry. J. Cultural Heritage 2010;11:163-171.

3. Prota A, Marcari G, Fabbrocino G, Manfredi G, Aldea C. Experimental in-plane behaviour of tuff masonry strengthened with cementitious matrix-grid composites. J Composites for Construction 2006;10(3):223-233.

4. Faella C, Martinelli E, Nigro E, Paciello S. Shear capacity of masonry walls externally strengthened by a cement-based composite material: an experimental campaign. $\mathrm{J}$ Constr Build Mater 2010;24:84-93.

5. Marcari G, Manfredi G, Prota A, Pecce M. In-plane shear performance of masonry panels strengthened with FRP. 8Composites Part B 2007;38:887-901.

6. CNR-DT200/2004. Guide for the design and construction of externally bonded FRP systems for strengthening existing structures. C.N.R., National Research Council, Italy, 2006 (in English), 2008 (in Italian).

7. Prota A, Manfredi G, Nardone F. Assessment of design formulas for in-Plane FRP strengthening of masonry walls. Journal of Composites for Construction 2008;12(6):643649.

8. Wei CQ, Zhou XG, Ye LP. Experimental study of masonry walls strengthened with CFRP. Structural Engineering and Mechanics 2007;25(6):675-690.

9. Zhao T, Zhang CJ, Xie J. Experimental Study on Earthquake Strengthening of Brick Walls with Continuos Carbon Fibre Sheet. Masonry International 2003;16(1):21-25.

10. Stratford T, Pascale G, Manfroni O, Bonfiglioli B. Shear strengthening masonry panels with sheet glass-fiber reinforced polymer. Journal of Composites for Construction 2004;8(5):434-443.

11. Eurocode 6. Design of masonry structures, Part 1-1: General rules for Building-Rules for reinforced and unreinforced masonry. European Committee for Standardization, CEN, Brussels, Belgium, 2005.

12. Valluzzi MR, Tinazzi D, Modena C. Shear behaviour of masonry panels strengthened by FRP laminates. J Constr Build Mater 2002;16:409-416. 
13. Tomaževič M. Shear resistance of masonry walls and Eurocode 6: shear versus tensile strength of masonry. Materials and Structures 2009;42:889-907.

14. Zhuge Y. FRP retrofitted URM walls under in-plane shear-review and assessment of available models. J of Composites for Construction 2010;14:43-54.

15. Krevaikas TD, Triantafillou TC. Computer-aided strengthening of masonry walls using fibre-reinforced polymer strips. Materials and Structures 2005;38:93-98.

16. Zhao T, Zhang CJ, Xie J. Shear behaviour of UCMW using CFRP sheet: a case study. The Masonry Society Journal 2004;22(1):87-95.

17. Alcaino $\mathrm{P}$, Santa-Maria $\mathrm{H}$. Experimental response of externally retrofitted masonry walls subjected to shear loading. J of Composites for Construction 2008;12(5):489-498.

18. Augenti N, Parisi F. Experimental data analysis on mechanical parameters of tuff masonry. Workshop on Design and Rehabilitation of Masonry Structures. In: Proceedings of Wondermasonry 2009, Lacco Ameno, Italy, October, 2009.

19. Faella G, Manfredi G, Realfonzo R. Cyclic Behaviour of Tuff Masonry Walls Under Horizontal Loading. In: Proceedings of 6th Canadian Masonry Symposium, Canada, June, 1992. p.317-328.

20. NTC (2008). Norme tecniche per le costruzioni, D.M. 14/01/2008, Gazzetta Ufficiale n. 29 del 04.02.2008, Suppl. Ord. n.30, 2008 (in Italian).

21. Frumento S, Magenes G, Morandi, P, Calvi G.M. Interpretation of experimental shear tests on clay brick masonry walls and evaluation of q-factors for seismic design, Eucentre Research, Report 2009/02, IUSS Press, Pavia, Italy.

22. Db Murature Unina-Dist. Raccolta dei dati esistenti sui parametri meccanici ed elastici delle murature. Responsabile Scientifico Prof. Augenti, N., Progetto esecutivo RELUIS 2005/2008, Linea di Ricerca 1, 2009, (www.reluis.unina.it).

23. Faella G, Manfredi G, Realfonzo R. Experimental evaluation of mechanical properties of old tuff masonry subjected to axial loading. In: Proceedings of $6^{\text {th }}$ Congresso Nazionale ASSI.R.C.CO, Prato, Italy, June, 1992. p.174-179. 


\section{Tables Caption}

Table 1. Experimental results on tuff masonry panels under shear-compression loading

Table 2. Results and comparisons between experimental and calculated shear strength contributions 


\section{List of Tables}

Table 1.

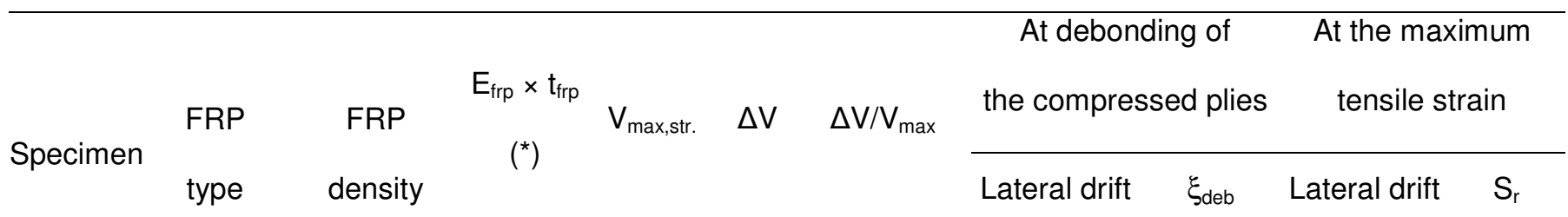

\begin{tabular}{|c|c|c|c|c|c|c|c|c|c|c|}
\hline & & & & & & & & & & \\
\hline & & & $\mathrm{kN} / \mathrm{mm}$ & $(\mathrm{kN})$ & $(\mathrm{kN})$ & (\%) & (\%) & (\%) & (\%) & $(\%)$ \\
\hline C1a & \multirow{4}{*}{ CFRP } & \multirow{2}{*}{ LD } & \multirow{2}{*}{38.4} & 156.7 & 24.7 & 19 & $0.50 \div 0.65$ & $70 \div 85$ & 1.40 & 15 \\
\hline C1b & & & & 188.9 & 56.9 & 43 & $0.75 \div 0.80$ & $85 \div 90$ & 1.30 & 10 \\
\hline C2a & & \multirow{2}{*}{$\mathrm{HD}$} & \multirow{2}{*}{76.8} & 180.6 & 48.6 & 37 & $0.35 \div 0.60$ & $70 \div 100$ & 1.30 & 20 \\
\hline $\mathrm{C} 2 \mathrm{~b}$ & & & & 227.0 & 95.0 & 72 & $0.75 \div 0.80$ & $70 \div 75$ & 1.90 & 10 \\
\hline G1a & \multirow{3}{*}{ GFRP } & LD & 7.3 & 155.8 & 23.8 & 18 & $0.45 \div 0.50$ & $80 \div 100$ & $1.00 \div 1.15$ & $20 \div 25$ \\
\hline G2a & & \multirow{2}{*}{ HD } & \multirow{2}{*}{14.6} & 179.5 & 47.5 & 36 & $0.80 \div 0.90$ & $95 \div 100$ & $1.30 \div 1.60$ & $25 \div 30$ \\
\hline G2b & & & & 147.4 & 15.4 & 12 & $0.25 \div 0.45$ & $75 \div 100$ & 0.90 & 11 \\
\hline
\end{tabular}

$\left({ }^{*}\right) t_{f}=0.0167$ for CFRP one ply (LD); $t_{f}=0.111 \mathrm{~mm}$ for GFRP one ply (LD)

$\mathrm{E}_{\mathrm{frp}}=230 \mathrm{GPa}$ for CFRP; $\mathrm{E}_{\mathrm{frp}}=66 \mathrm{GPa}$ for GFRP 
Table 2.

\begin{tabular}{|c|c|c|c|c|c|c|c|c|c|c|c|c|c|}
\hline \multirow{3}{*}{$\begin{array}{c}\text { Specime } \\
n\end{array}$} & \multicolumn{2}{|c|}{$\begin{array}{c}\text { Experimental } \\
\text { data }\end{array}$} & \multicolumn{5}{|c|}{ Computed values } & \multicolumn{6}{|c|}{ Comparative analysis } \\
\hline & $\mathrm{N}_{0}$ & $\mathrm{~V}_{\max , \mathrm{str}}$ & $\begin{array}{c}F_{\text {frp }} \\
\text { [Eq. (4)] }\end{array}$ & $\begin{array}{l}\mathrm{N}_{\mathrm{m}, \mathrm{frp}} \\
\text { [Eq. } \\
(6)]\end{array}$ & $\begin{array}{l}\mathrm{V}_{\mathrm{frp}} \\
{[\mathrm{Eq} .} \\
(5)]\end{array}$ & $\begin{array}{l}\mathrm{V}_{\mathrm{m}} \\
{[\mathrm{Eq} .} \\
(7)]\end{array}$ & $\begin{array}{c}\mathrm{V}_{\mathrm{SM}} \\
\text { [Eq. (9)] }\end{array}$ & $\frac{\mathrm{V}_{\mathrm{SM}}}{\mathrm{V}_{\text {max,str. }}}$ & $\frac{\mathrm{V}_{\mathrm{m}}^{\prime}}{\mathrm{V}_{\text {max str. }}}$ & $\frac{V_{\text {frp }}}{V_{\text {max,str. }}}$ & $\frac{\mathrm{V}_{\mathrm{m}}^{\prime}-\mathrm{V}_{\max }}{\mathrm{V}_{\max }}$ & $\Delta \mathrm{V}^{\prime}$ & $\frac{V_{\text {frp }}}{\Delta V^{\prime}}$ \\
\hline & $(\mathrm{kN})$ & $(\mathrm{kN})$ & $(\mathrm{kN})$ & $(\mathrm{kN})$ & $(\mathrm{kN})$ & $(\mathrm{kN})$ & $(\mathrm{kN})$ & $(-)$ & $(\%)$ & $(\%)$ & $(\%)$ & $(\mathrm{kN})$ & $(-)$ \\
\hline C1a & 379 & 156.7 & 41.2 & 30.7 & 28.0 & 133.8 & 161.8 & 1.03 & 85 & 18 & 1.4 & 22.9 & 1.22 \\
\hline C1b & 391 & 188.9 & 45.6 & 33.9 & 31.0 & 136.2 & 167.2 & 0.89 & 72 & 16 & 3.2 & 52.7 & 0.59 \\
\hline $\mathrm{C} 2 \mathrm{a}$ & 384 & 180.6 & 85.3 & 61.0 & 58.0 & 139.1 & 197.1 & 1.09 & 77 & 32 & 5.4 & 41.5 & 1.40 \\
\hline $\mathrm{C} 2 \mathrm{~b}$ & 387 & 227.0 & 63.2 & 46.0 & 43.0 & 136.6 & 179.7 & 0.79 & 60 & 19 & 3.5 & 90.4 & 0.48 \\
\hline G1a & 391 & 155.8 & 12.8 & 9.3 & 8.7 & 132.6 & 141.3 & 0.91 & 85 & 6 & 0.5 & 23.2 & 0.37 \\
\hline G2a & 384 & 179.5 & 25.3 & 18.3 & 17.2 & 132.4 & 149.6 & 0.83 & 74 & 10 & 0.3 & 47.1 & 0.37 \\
\hline G2b & 386 & 147.4 & 22.1 & 15.8 & 14.9 & 132.8 & 147.7 & 1.00 & 90 & 10 & 0.6 & 14.6 & 1.02 \\
\hline
\end{tabular}




\section{Figures Caption}

Figure 1. Test set-up: (a) FRP shear strengthening; (b) anchorage system of the diagonal plies

Figure 2. Comparison of shear force-horizontal displacement curves: (a) CFRP; (b) GFRP

Figure 3. Panel C1a: compressive (a) and tensile (b) strain profiles on side A; (c) V- $\delta$ curve

Figure 4. Panel C1b: compressive (a) and tensile (b) strain profiles on side A; (c) V- $\delta$ curve

Figure 5. Panel C2a: compressive (a) and tensile (b) strain profiles on side A; (c) V- $\delta$ curve

Figure 6. Panel C2b: compressive (a) and tensile (b) strain profiles on side A; (c) V- $\delta$ curve

Figure 7. Panel G1a: compressive (a) and tensile (b) strain profiles on side A; (c) V- $\delta$ curve

Figure 8. Panel G2a: compressive (a) and tensile (b) strain profiles on side B; (c) V- $\delta$ curve

Figure 9. Panel G2b: compressive (a) and tensile (b) strain profiles on side A; (c) V- $\delta$ curve

Figure 10. Damage of panel (a) C1b, 1.90\% drift; (b) C2b, 1.40\% drift; (c) G1a, 1.2\% drift

Figure 11. Adopted truss model

Figure 12. Shear strength contribution from FRP of panels (a) C1, (b) C2; (c) G1a; (d) G2

Figure 13. (a) Results of shear strength contributions from FRP and masonry; (b) N-V interaction diagram 


\section{List of Figures}

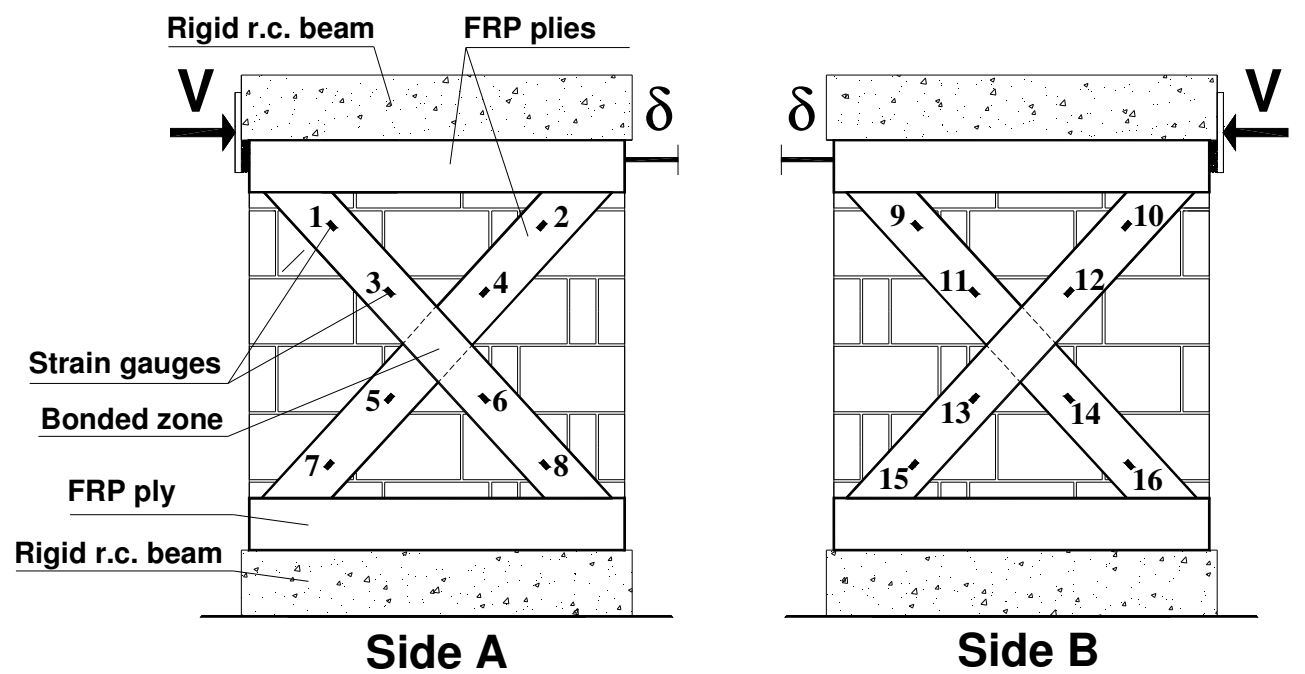

Figure 1. (a)

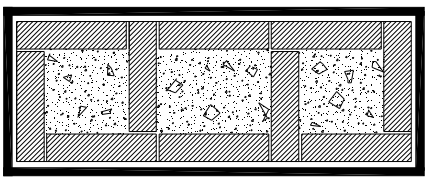

FULL WRAPPING

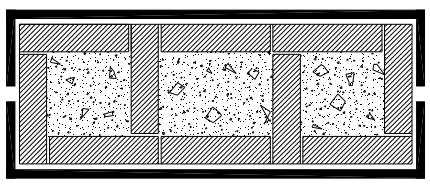

U-WRAPPING

(b)

Figure 1. (b) 


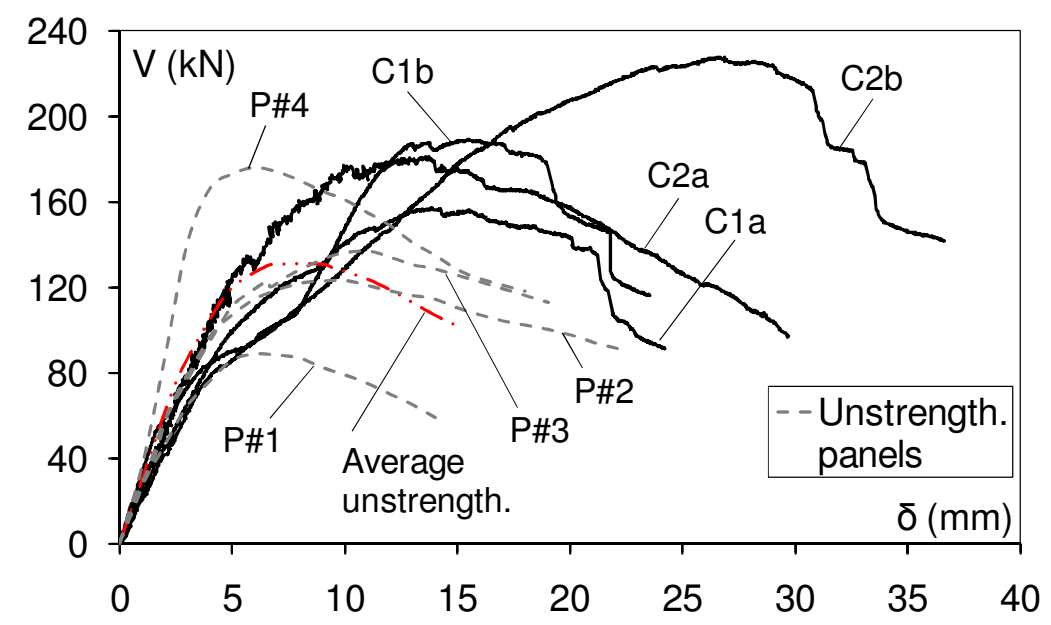

Figure 2. (a)

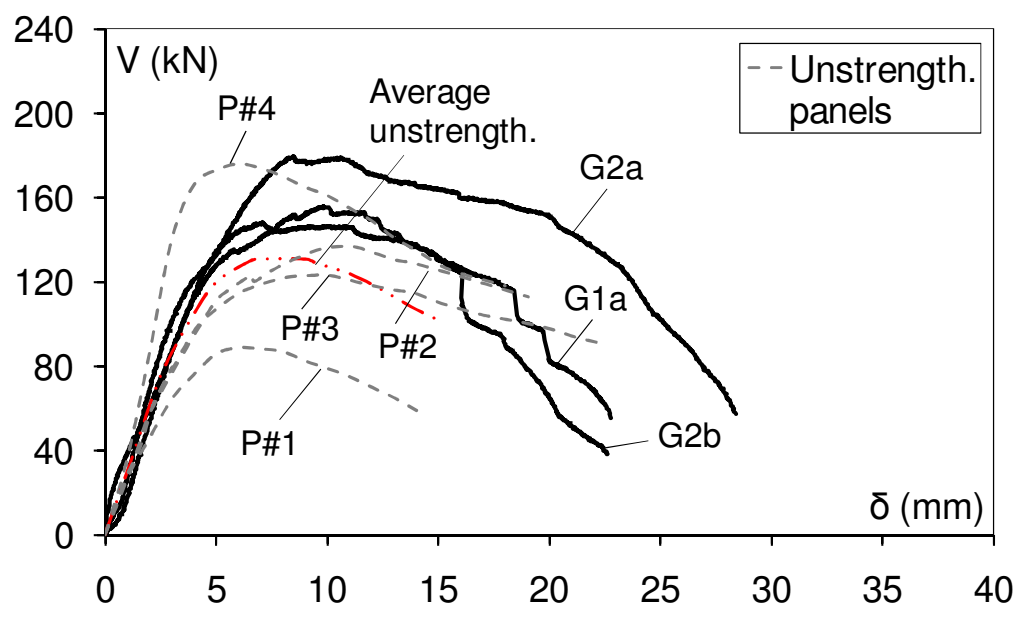

Figure 2. (b) 


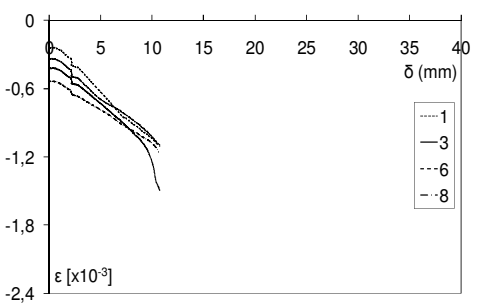

(a)

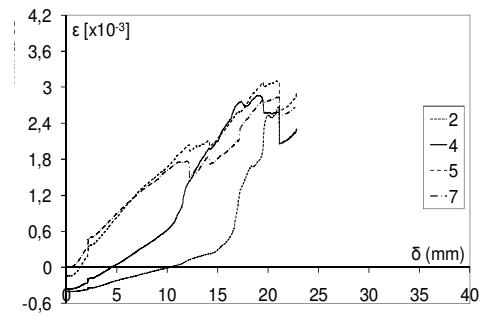

(b)

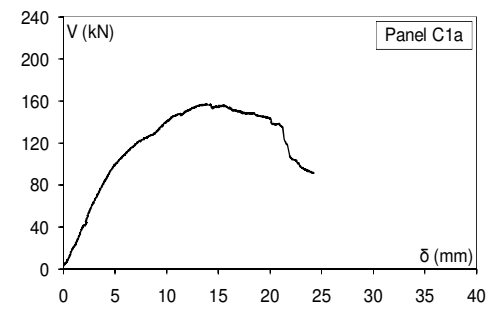

(c)

Figure 3.

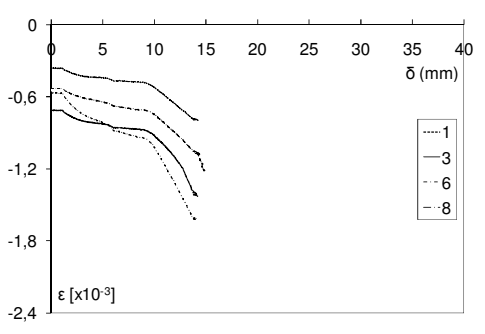

(a)

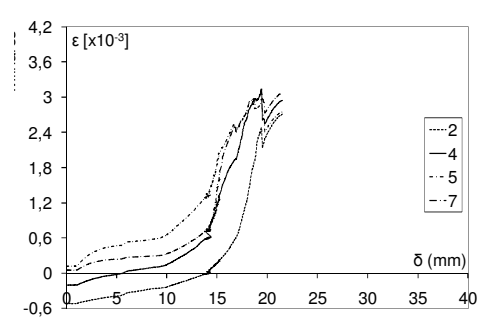

(b)

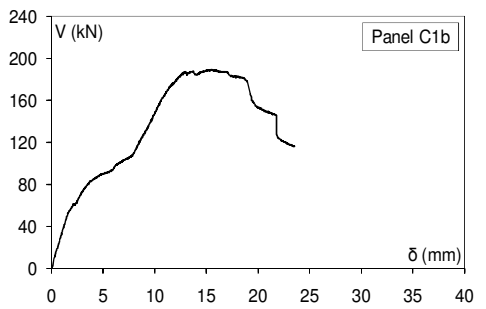

(c)

Figure 4.

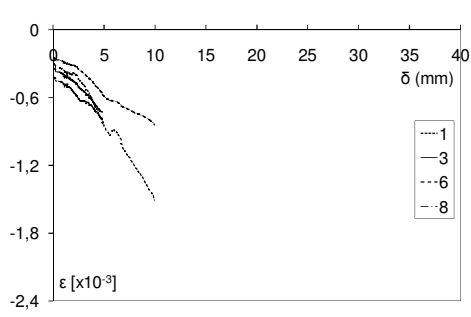

(a)

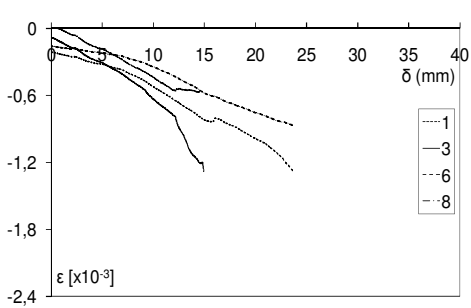

(a)

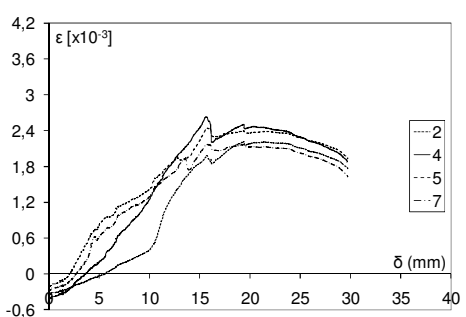

(b)

Figure 5.

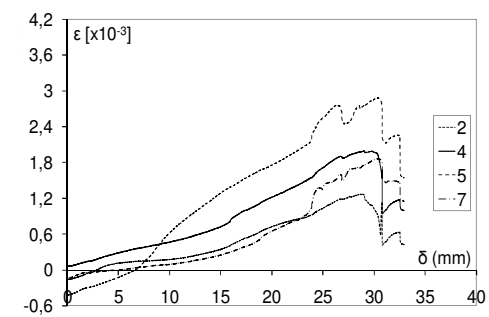

(b)

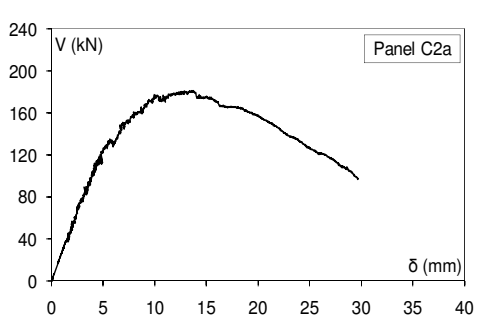

(c)

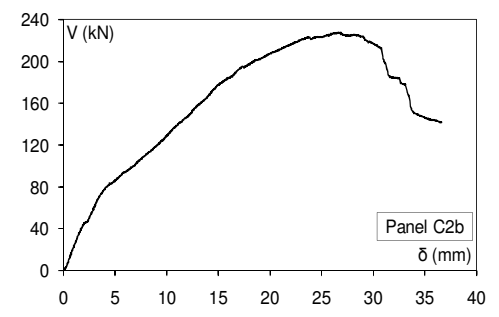

(c)

Figure 6. 


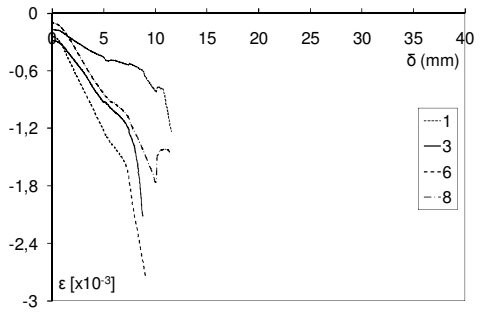

(a)

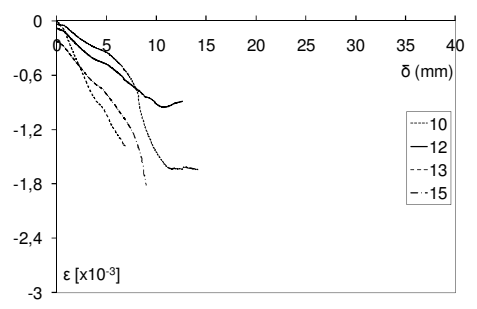

(a)

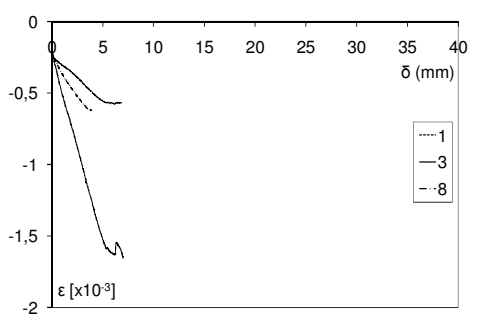

(a)

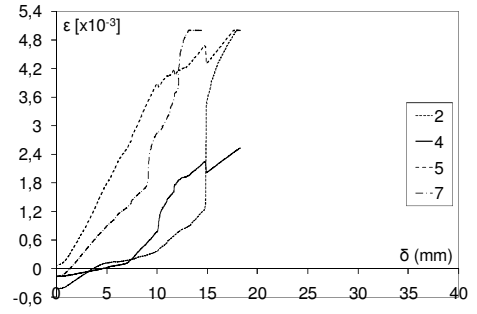

(b)

Figure 7.

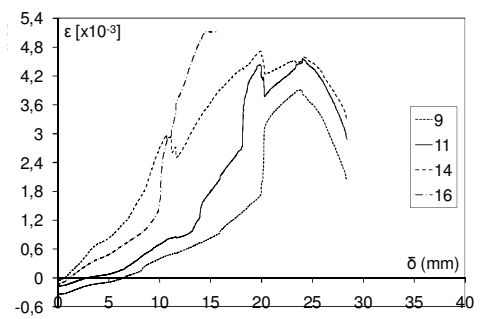

(b)

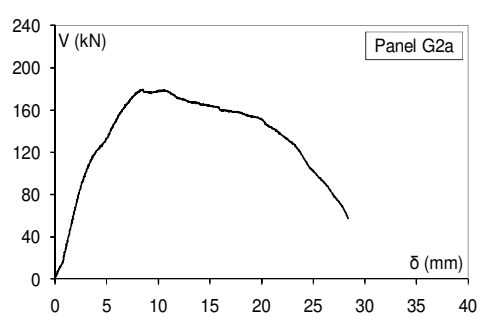

(c)

Figure 8.

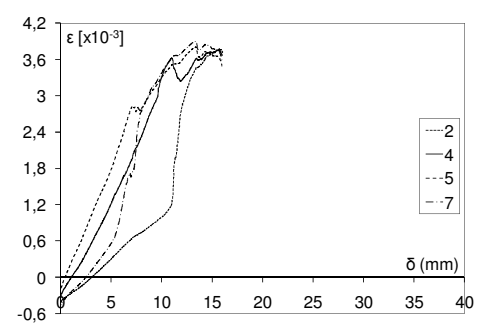

(b)

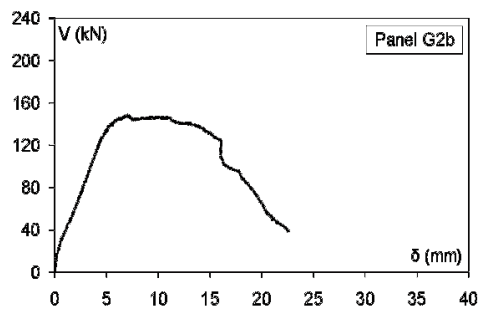

(c)

Figure 9. 


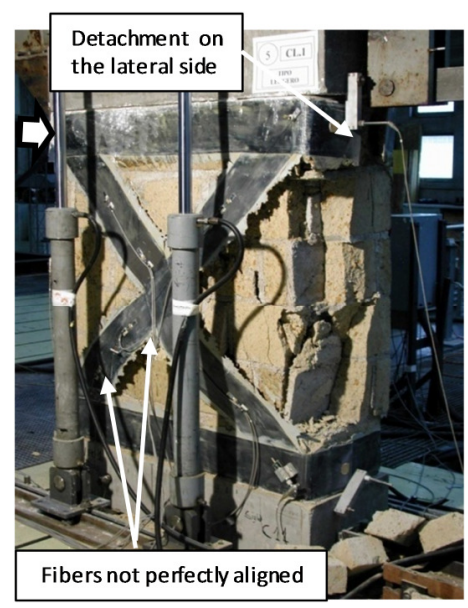

Figure 10. (a)

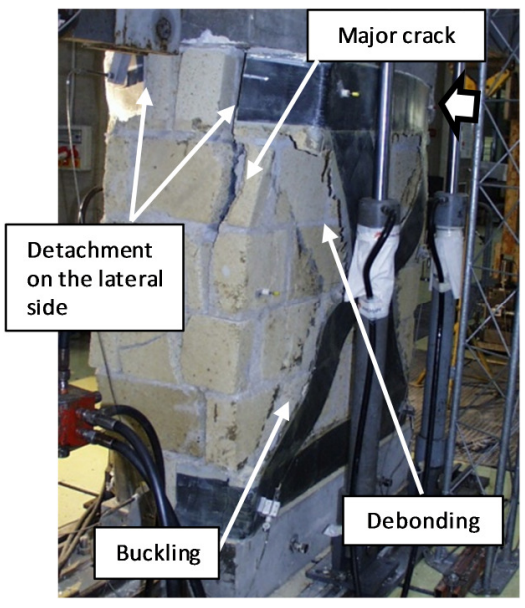

Figure 10. (b)

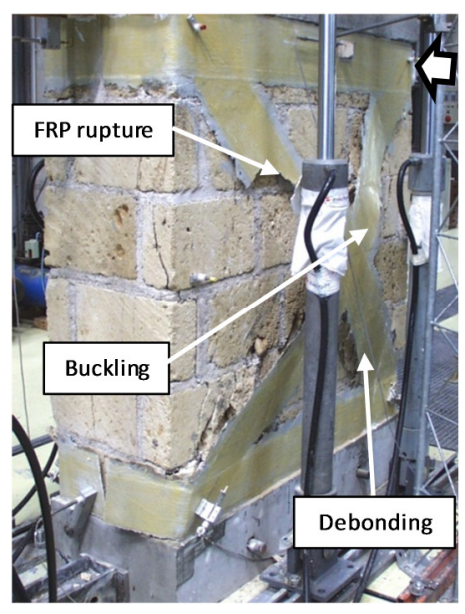

Figure 10. (c) 


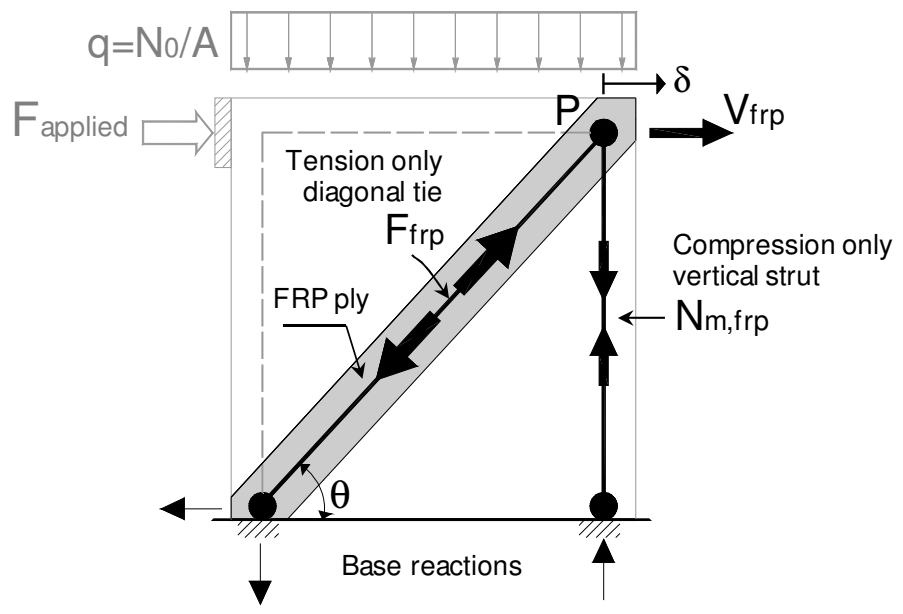

Figure 11.

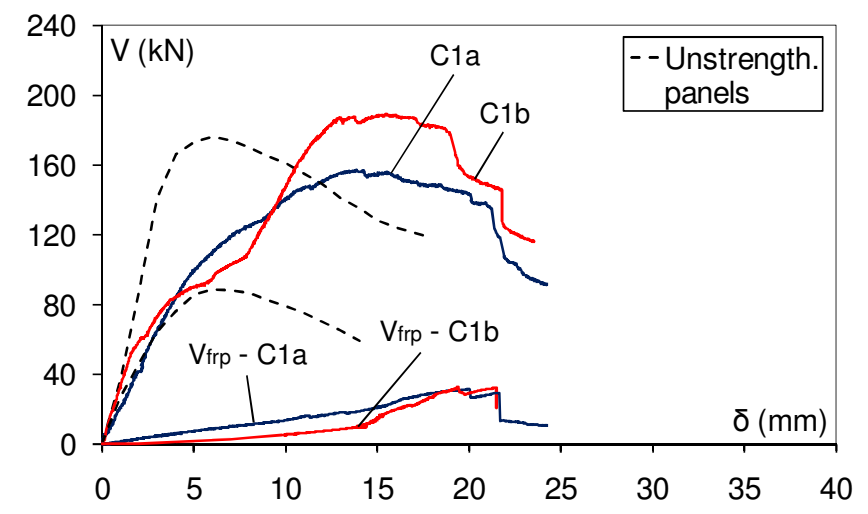

Figure 12. (a)

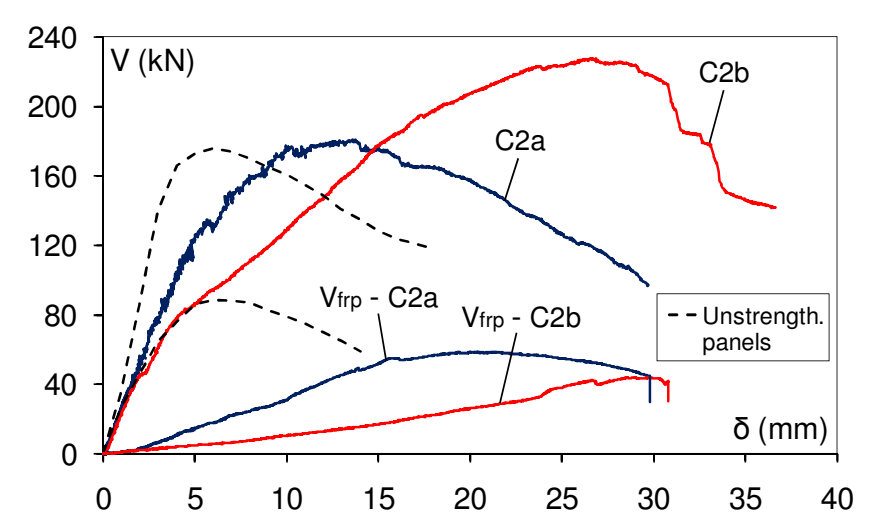

Figure 12. (b) 


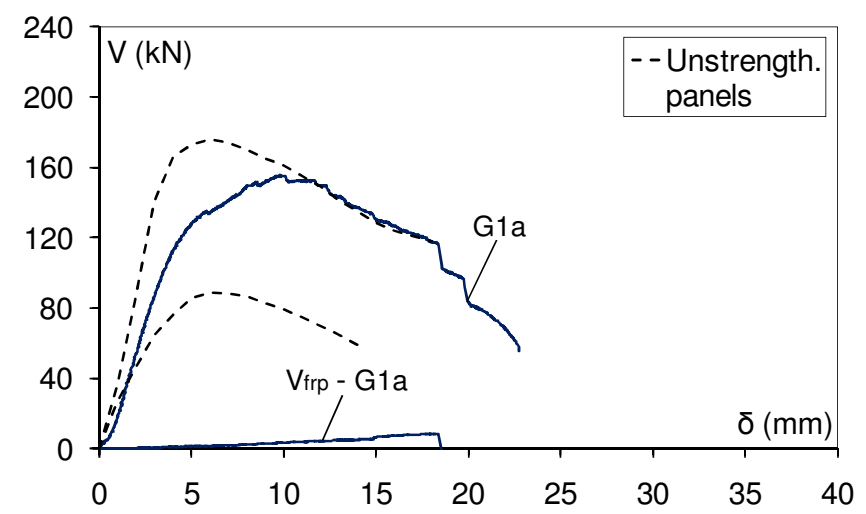

Figure 12. (c)

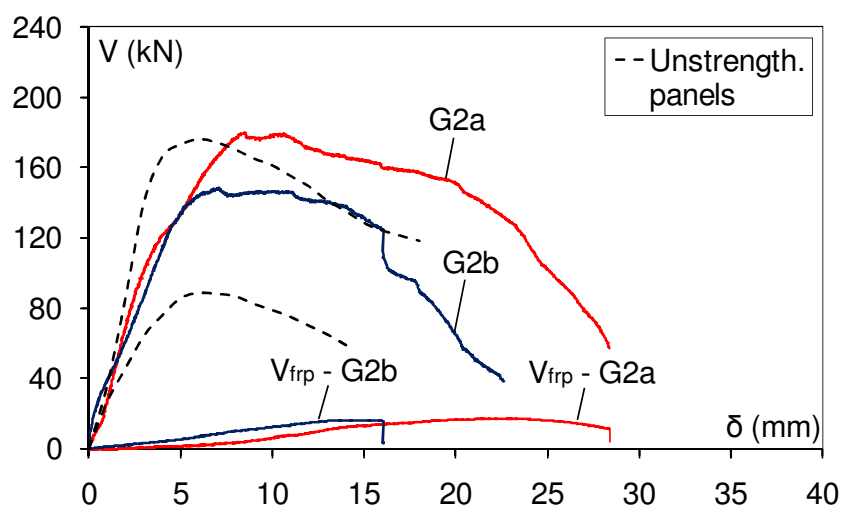

Figure 12. (d)

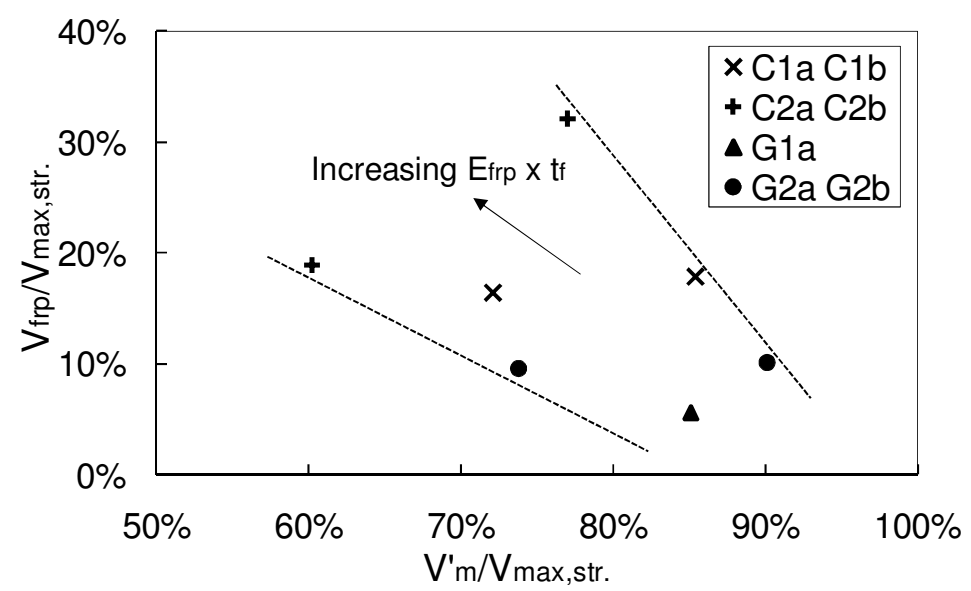

Figure 13. (a) 


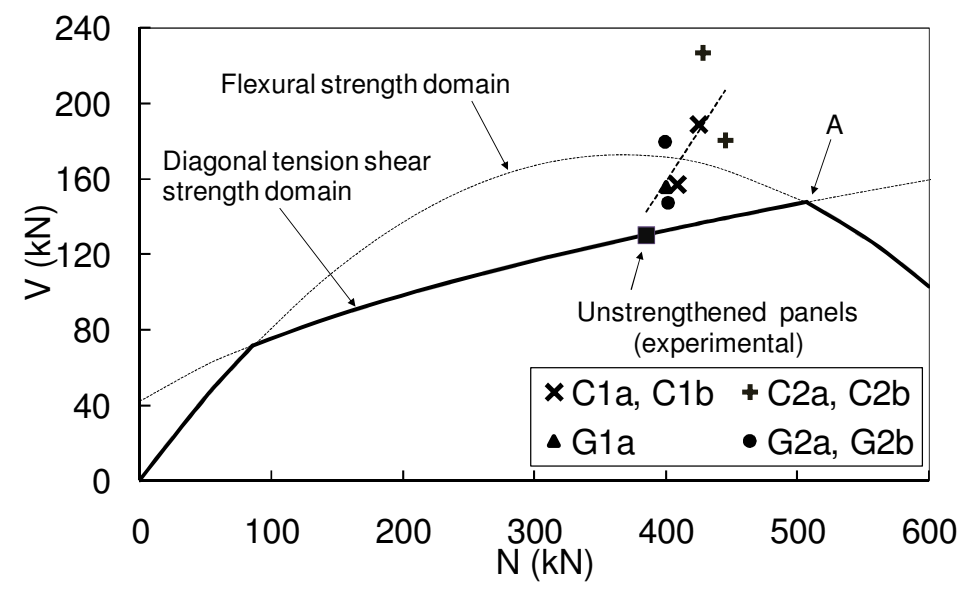

Figure 13. (b) 